\title{
The Longitudinal Stability and Predictive Capability of Positive and Negative Self-Schemas in a Multi-Informant Study of Child and Adolescent Depressive Symptoms and Life Satisfaction
}

\section{Kathlyn M. Cherry ${ }^{1}$ (D) Margaret N. Lumley ${ }^{1}$}

Accepted: 22 July 2019 / Published online: 31 July 2019

(C) Springer Nature Switzerland AG 2019

\begin{abstract}
Research has established that negative self-schemas are potent risk factors for depressive symptoms among children and adolescents. However, few studies have examined whether positive self-schemas provide unique information about children and adolescents' depressive symptoms and their well-being. Further, examining the stability of cognitive content during this developmental transition is also relevant. Informed by positive (clinical) psychology and cognitive-developmental frameworks, this study examined a) the longitudinal stability of children and adolescents' self-schemas and b) the prospective associations of positive and negative self-schemas to children and adolescents' depressive symptoms and life satisfaction in a community sample of 139 children and adolescents $\left(M_{\text {age }}=11.20, S D=1.21\right)$ and their parent/guardian. Results provided preliminary evidence that negative and positive self-schemas exhibit stability over time. Positive self-schemas also predicted unique variance in children and adolescents' depressive symptoms, above and beyond negative self-schemas. Only negative self-schemas were uniquely associated with children and adolescents' life satisfaction over time. These results suggest there may be utility in incorporating positive selfschemas into models of child and adolescent depression. As well, these results may provide important information regarding appropriate timing for the prevention of child and adolescent depression and bolstering of well-being.
\end{abstract}

Keywords Self-schemas · Depressive symptoms · Life satisfaction · Child and adolescent mental health · Positive psychology

Kathlyn M. Cherry

kcherry@uoguelph.ca

1 Department of Psychology, University of Guelph, Guelph, ON, Canada 


\section{Introduction}

The transition from childhood to adolescence is a particularly critical zenith for emotional difficulties with prevalence of subsyndromal depressive symptoms at 20 to $50 \%$ (Kessler et al. 2001) and rates of depression increasing six-fold between 10 and 14 years (Hankin et al. 1998; Petersen et al. 2018). Both depressive symptoms and disorder are associated with heightened risk for future depressive episodes, poor psychosocial functioning, and suicide ideation and attempts (Fergusson et al. 2005; Georgiades et al. 2006; Gotlib et al. 1995). The absence of ostensibly positive indicators of functioning (e.g., positive self-schemas, happiness), as opposed to the presence of negative indicators (e.g., negative self-schemas, dysphoria), may be more instrumental in identifying the risk for, maintenance of, and recovery from depressive symptoms and disorder (Jaenicke et al. 1987; Keyfitz et al. 2013; McClain and Abramson 1995). Yet, a paucity of research has simultaneously considered positive and negative variables in the context of child and adolescent depression and well-being. Conveying more holistic models of child and adolescent well-being may dispel the assumption that mental health is merely the absence of psychopathology (Keyes 2002, 2006, 2007; Pawelski 2016). Toward a more holistic view, the current research considers the respective roles of positive and negative self-schemas in uniquely contributing to aspects of children and adolescents' depressive symptoms and well-being.

\section{Self-Schemas and Child and Adolescent Depression}

Research has stablished that negative self-schemas confer risk for child and adolescent depression (Abela and Hankin 2008). Beck's $(1967,1987)$ cognitive theory of depression posits self-schemas explain the onset, maintenance, and recovery from depression. Self-schemas refer to core mental representation of the self and can be either positive (e.g., "I believe in myself") or negative (e.g., "I am worthless") in content valence (Dozois and Beck 2008). Although self-schemas have both contextual (i.e., positive vs. negative) and structural (i.e., tight-knit vs. loose-knit) features, the former are the focus of the present study. Extant research regarding self-schemas and depressive symptoms among youth has focused almost exclusively on the role of negative self-schemas. This research suggests that negative self-schemas are associated with increased risk and maintenance of depressive symptoms among children and adolescents (Abela and Sullivan 2003; Calvete et al. 2015; Carter and Garber 2011; Garber et al. 1993; Hammen and Zupan 1984; Hankin et al. 2004; Kercher et al. 2009; Lewinsohn et al. 2001; Lumley and Harkness 2007; Timbremont and Braet 2006). For example, Garber et al. (1993) found negative self-schemas were associated with depressive symptoms in a sample of approximately 700 adolescents.

By contrast, the potential unique contribution of positive self-schemas is comparatively absent from empirical and theoretical conceptualizations of youth depression. Positive self-schemas are defined as positive core beliefs about the self, such as "I believe things will turn out well" (Keyfitz et al. 2013). The absence of positive selfschema consideration may be attributable to the misperception that positive cognition is merely the inverse of negative cognition, despite evidence that positive self-schemas 
exist on a continuum distinct from negative self-schemas (MacLeod and Moore 2000) and theoretical support for the distinction between positive and negative constructs in depression (i.e., tripartite model; Clark and Watson 1991). Only a handful of studies have examined how positive self-schemas may provide unique information about depressive symptoms in youth (e.g., Friedmann et al. 2016; Keyfitz et al. 2013). Such studies have provided preliminary evidence that a lack of positive self-schemas may have more etiological importance in models of youth depression than the presence of negative self-schemas (Keyfitz et al. 2013; Goldstein et al. 2015; McClain and Abramson 1995; Whitman and Leitenberg 1990). For example, Keyfitz et al. (2013) found positive self-schemas explained more variance in adolescents' depressive symptoms than negative self-schemas. However, a longitudinal study failed to replicate these results, finding only negative self-schemas were longitudinally associated with youths' depressive symptoms (Friedmann et al. 2016). Thus, emerging from extant research is an increasing awareness that positive and negative self-schemas may have differential trajectories and associates. Aligning with cognitive-developmental (Beck 1967, 1987; Dozois and Beck 2008), positive (clinical) psychology (Johnson and Wood 2017; Seligman and Csikszentmihalyi 2000; Wood and Tarrier 2010), and positive youth development (Larson 2000, 2006; Lerner et al. 2005) perspectives, the present study considers the dissociative capabilities of self-schemas and stands to contribute to a more fine-grained and inclusive understanding of youths' functioning.

\subsection{Self-Schemas and Child and Adolescent Life Satisfaction}

Given positive development and psychopathology are theorized to operate on related yet separate continua (Keyes 2006; O’Connor et al. 2011; Renshaw et al. 2014), explicit consideration of variables that contribute to positive development is necessary and may benefit all youth, including those at risk for developing psychopathology and those who convey a general disengagement with life (Larson 2000; Wood and Tarrier 2010). The present study considered life satisfaction as an index of youths' well-being. Life satisfaction is defined as an individuals' cognitive evaluation of how satisfied they are with the quality of their life globally and in particular domains (Diener 2000). Extant research implies life satisfaction among children and adolescents is positively related to a host of desirable characteristics and outcomes (see Huebner et al. 2004 and Proctor et al. 2009 for reviews) and negatively associated with adverse developmental outcomes such as aggression (Valois et al. 2001), drug use (Zullig et al. 2001), and depression (McKnight et al. 2002). Youths' life satisfaction may also mitigate the diathesis-stress cascade between stressful experiences and internalizing psychopathology (McKnight et al. 2002; Park 2004). Thus, life satisfaction may not merely be an epiphenomenon, but may protect against psychopathology and engage youth in processes of positive development.

To date, the relative contributions of positive and negative self-schemas to youths' experiences of positive development - particularly life satisfaction - have not been extensively examined. However, wider cognitive research suggests examining these relations may be useful. For example, individuals high in life satisfaction have been shown to exhibit tightly connected positive semantic networks (Robinson and Kirkeby 2005). An additional study found positive thinking (e.g., optimism and self-esteem) predicted happiness over time in a sample of over 600 adolescents (Caprara et al. 
2006). Finally, findings from a recent cross-sectional study suggest positive selfschemas are uniquely associated with youths' ratings of life satisfaction, beyond negative self-schemas (Tomlinson et al. 2016). Indeed, Renshaw and colleagues (Renshaw et al. 2014, p. 15) suggest a fundamental goal of the positive psychology paradigm is to understand the development of positive self-schemas in relation to youths' ability to thrive. A longitudinal replication investigating the relative contributions of positive and negative self-schemas to life satisfaction is thus both conceptually and practically relevant.

\subsection{The Stability of Self-Schemas during Childhood and Adolescence}

Research characterizing the stability of self-schemas across development is essential to informing appropriate timing of interventions aimed at reducing vulnerability to depression and inciting well-being. Although much is known about the stability of selfschemas in adults (e.g., Calvete et al. 2012; Dozois and Dobson 2001), and to a lesser extent children (e.g., Goldstein et al. 2015; Hayden et al. 2013), scarce research has examined self-schema stability during the pivotal developmental transition from childhood to adolescence. Further, although the stability of adolescents' depressotypic selfschemas has accumulated (Abela and Hankin 2008; Hankin 2008; Lumley et al. 2012), little is known about the general stability of themes that constitute self-schemas in typically developing children and adolescents. This question bears importance given children and adolescents may be experimenting with identity formation and exploration throughout this phase of development (Brinthaupt and Lipka 2002; Meeus 2011; Swanson et al. 1998). If self-schema themes are established during childhood and adolescence, this may be an ideal period to intervene with maladaptive self-schema development and promote adaptive self-schema growth.

Goldstein et al. (2015) and Hayden et al. (2013) have found modest evidence for the stability of positive and negative cognitive processing styles among children followed from ages six through nine ( $r$ 's ranging from .10 to .39). More recently, Friedmann et al. (2016) found negative and positive self-schema content and structure exhibited stability over time in youth aged 9 to 14 ( $r$ 's ranging from .29 to .58 ). However, only a quarter of participants $(n=50)$ were available at follow-up, with high variability between initial and follow-up data collection. Given these limitations, as well as calls for understanding the trajectory of areas of adolescent competency such as positive self-schemas (Dulman and Ong 2006), further consideration of child and adolescent self-schema stability is warranted.

\subsection{The Current Study: Objectives and Hypotheses}

The objective of this study was to employ a multi-informant, longitudinal design to examine the stability and unique longitudinal associations of self-schemas in relation to children and adolescents' depressive symptoms and life satisfaction. In this way, the current study may contribute to the accumulation of knowledge regarding self-schemas and adolescents' functioning, which is important in terms of replicability of findings and use in future reviews and meta-analyses (see Maxwell et al. 2015 for review). Specifically, this study sought to understand: a) whether children and adolescents' selfschemas show evidence of stability; and b) whether positive self-schemas provide 
unique information about aspects of youths' functioning (as reported on by the youth and their parent/guardian) beyond information afforded by negative self-schemas. The following hypotheses were proposed:

1. Stability of child and adolescent self-schemas. Based on findings with children (Goldstein et al. 2015; Hayden et al. 2013) and adults (Dozois and Dobson 2001) and a more recent study in an adolescent sample (Friedmann et al. 2016), it was hypothesized that children and adolescents' positive and negative self-schemas would exhibit moderate levels of stability over time (i.e., no statistically significant average changes in mean-levels over time).

2. Self-schemas as prospective predictors of depressive symptoms. It was hypothesized that comparatively lower levels of positive self-schemas and higher levels of negative self-schemas at Time 1 would be prospectively associated with higher levels of youth-reported depressive symptoms (YR-DS) at Time 2. Moreover, positive self-schemas at Time 1 were hypothesized to be uniquely associated with YR-DS at Time 2, contributing unique variance beyond negative self-schemas at Time 1.

3. Self-schemas as prospective predictors of life satisfaction. It was hypothesized that comparatively higher levels of positive self-schemas and lower levels of negative self-schemas at Time 1 would be longitudinally associated with higher levels of youth-reported life satisfaction (YR-LS) at Time 2. Further, positive selfschemas at Time 1 were hypothesized to be uniquely associated with YR-LS at Time 2, contributing unique variance beyond negative self-schemas at Time 1.

\section{Method}

\subsection{Participants}

Participants were recruited from elementary schools in southern Ontario. A community sample of 139 child and adolescent girls $(n=71)$, boys $(n=64)$, and undisclosed $(n=4)$ aged 8 to $13(M=11.20, S D=1.21)$ and their parent/guardian participated. Participants were in Grades 4 through 8. Reported ethnic background was as follows: Caucasian $(63.9 \%, n=85)$, Asian $(13.5 \%, n=18)$, African American or Caribbean $(3.0 \%, n=4)$, Hispanic or Latino (3.8\%, $n=5)$, First Nations/Inuit/Métis or Middle Eastern or South Asian $(2.3 \%, n=3)$, and "Other" $(13.5 \%, n=18)$. Data collection commenced in the Fall of 2012. A total of 413 consent packages were sent home to parents/guardians and 139 were returned providing parental/guardian consent and youth assent (34\% response rate). The second wave of data collection took place approximately six months later in the Spring of 2013 ( $M=185, R=175-194$ days).

\subsection{Measures}

Schema Questionnaire for Children (SQC; Stallard and Rayner 2005) The SQC is a 15item self-report measure of negative self-schema content in youth (e.g., "I am a failure") with items rated from 1 (completely untrue of me) to 6 (describes me perfectly). Higher scores reflect higher levels of negative self-schemas. The SQC 
possesses strong face validity and concurrent validity with the Young Schema Questionnaire (Stallard and Rayner 2005) and acceptable reliability in adolescent samples (Friedmann et al. 2016; Keyfitz et al. 2013; Lumley et al. 2012; Rijkeboer and de Boo 2010; Stallard 2007; Stallard and Rayner 2005). The SQC showed adequate reliability in the current study (T1 $\alpha=.83, \mathrm{~T} 2 \alpha=.73$ ).

Positive Schema Questionnaire (PSQ; Keyfitz et al. 2013) The PSQ is a 20-item selfreport measure assessing five positive self-schema themes with items rated from 1 (completely untrue of me) to 6 (describes me perfectly). Higher scores represent higher levels of positive self-schemas. The five positive self-schema themes include: optimism (e.g., "I believe things will turn out well"), trust (e.g., "I trust other people"), selfefficacy (e.g., "I can respond well to challenges"), success (e.g., "If I try hard I can usually do well"), and worthiness (e.g., "I believe in myself"). The PSQ has demonstrable face, predictive, and discriminant validity and strong reliability (Keyfitz et al. 2013) and has been used successfully to measure positive self-schemas in children and adolescents (Friedmann et al. 2016; Keyfitz et al. 2013; Tomlinson et al. 2016). In this study, the PSQ showed good internal consistency (T1 $\alpha=.94$, T2 $\alpha=.95$ ). Each individual subscale also showed acceptable internal consistency as follows: optimism (T1 $\alpha=.87, \mathrm{~T} 2 \alpha=.85)$, trust (T1 $\alpha=.86$, T2 $\alpha=.90)$, self-efficacy (T1 $\alpha=.94, \mathrm{~T} 2$ $\alpha=.86$ ), success (T1 $\alpha=.93$, T2 $\alpha=.88$ ), and worthiness (T1 $\alpha=.90, \mathrm{~T} 2 \alpha=.88$ ).

Children's Depression Inventory (CDI; Kovacs 1981) To assess YR-DS, the 27-item CDI self-report questionnaire was employed, assessing the behavioural, affective, and cognitive symptoms of depression among children and adolescents. For each item, participants chose one of three statements that best indicated how they feel. Each item was rated using a three-point scale: 0 (no or low symptoms), 1 (mild symptoms), or 2 (severe symptoms). In the current study, the CDI demonstrated excellent reliability (T2 $\alpha=.90)$.

Strengths and Difficulties Questionnaire, Emotional Symptoms Subscale (SDQ; Goodman 1997) The current study measured youth-reported emotional symptoms (YR-ES) and parent-reports of their youths' emotional symptoms (PR-ES) with the Emotional Symptoms subscale at Time 1. This subscale is comprised of 5 items (e.g., "I am often unhappy, depressed or tearful") rated from 0 (not true) to 2 (certainly true). The SDQ is a psychometrically sound measure with satisfactory internal consistency and test-retest reliability (Goodman 2001; Muris et al. 2003). The Emotional Symptoms subscale is highly correlated with youth $(r=.74)$ and parent $(r=.70)$ reports of adolescents' internalizing symptoms as measured by the Child Behavior Checklist (CBCL) and depression scales such as the CDI ( $r=.67$; Muris et al. 2003). The Emotional Symptoms subscale demonstrated acceptable reliability at Time 1 for YRES $(\alpha=.75)$ and PR-ES $(\alpha=.74)$ and predictive validity with regard to YR-DS at Time $2(r=.53$ and $r=.39$, respectively).

Brief Multidimensional Students' Life Satisfaction Scale (BMSLSS; Seligson et al. 2003) YR-LS and parent-reports of their youths' life satisfaction (PR-LS) were employed using the 6-item BMSLSS. Items were rated on a 7-point Likert scale $(1=$ Terrible, $4=$ Mixed, $7=$ Delighted ) with higher scores indicating greater levels of life 
satisfaction. The BMSLSS provides a measure of overall and domain-specific life satisfaction (e.g., satisfaction with family, friends, school, self, and living circumstances). In this study, the BMSLSS demonstrated good internal consistency for YRLS (T1 $\alpha=.89, \mathrm{~T} 2 \alpha=.87)$ and PR-LS (T1 $\alpha=.87)$.

\subsection{Procedure}

Upon clearance from the University Research Ethics Board, students from participating elementary schools were provided with an information and consent package for the study to deliver to their parent/guardian. Upon parental/guardian consent, the first wave of data collection commenced. Participants completed measures (SQC, PSQ, SDQ, BMSLSS) at school on netbooks separated by privacy shields. Parents/guardians completed measures of their youths' functioning (SDQ and BMSLSS) at home and returned them by mail. YR-ES and PR-ES were gathered using the SDQ Emotional Symptoms subscale at Time 1. The SDQ was thus employed as a proxy variable to control for YR-DS at Time 2 as measured by the CDI. Participants completed the second wave of data collection (SDQ, PSQ, CDI, BMSLSS) in a similar fashion approximately six months later.

\section{Results}

\subsection{Descriptive Statistics}

Preliminary Analyses Means and standard deviations are presented in Table 1. Age and gender were examined to determine the need for covariation in statistical analyses. No statistically significant relations emerged among correlations of age and the central study variables (all $p$ 's $>.05$ ). Independent-samples $t$-tests were conducted to evaluate associations among the central study variables based on participant gender. Girls reported significantly higher levels of YR-ES at Time $1(M=3.73, S D=2.50)$ compared to boys $(M=2.76, S D=2.41), t(119)=2.15, p=.03$, Cohen's $d=.37$. Thus, multivariate models including YR-ES at Time 1 included gender as a covariate.

\subsection{Univariate Relations}

Youth Functioning Over Time Correlations were examined to determine relations over time between YR-ES, PR-ES, YR-LS and PR-LS at Time 1 and YR-DS and YR-LS at Time 2 (see Table 2). YR-ES and PR-ES at Time 1 were significantly and positively related to YR-DS at Time $2(r=.53, p<.001$ and $r=.39, p<.001$, respectively). Similarly, YR-LS and PR-LS at Time 1 were significantly and positively related to YR-LS at Time $2(r=.51, p<.01$ and $r=.33, p<.01$, respectively).

Stability of Negative Self-Schemas Negative self-schemas at Time 1 were significantly and positively correlated with negative self-schemas at Time $2(r=.51, p<.001$, see Table 2). A paired samples $t$-test was conducted to examine mean differences between total negative self-schemas at Time 1 and Time 2 and was not statistically significant 
Table 1 Descriptive statistics for study variables of interest

\begin{tabular}{|c|c|c|c|c|}
\hline & \multicolumn{2}{|l|}{ Time 1} & \multicolumn{2}{|c|}{ Time 2} \\
\hline & $M$ & $S D$ & $M$ & $S D$ \\
\hline Negative self-schemas & 34.80 & 11.13 & 33.30 & 8.58 \\
\hline Positive self-schemas & 89.17 & 19.18 & 92.48 & 17.05 \\
\hline Self-efficacy & 17.45 & 4.75 & 18.33 & 4.00 \\
\hline Success & 20.36 & 4.59 & 20.79 & 3.45 \\
\hline Trust & 15.34 & 4.62 & 15.80 & 5.24 \\
\hline Optimism & 16.88 & 4.36 & 17.99 & 4.05 \\
\hline Worthiness & 19.14 & 4.73 & 19.57 & 4.06 \\
\hline \multicolumn{5}{|c|}{ Youths' emotional/depressive symptoms } \\
\hline Youth-report & 3.26 & 2.50 & 6.46 & 7.10 \\
\hline Parent-report & 2.30 & 2.24 & - & - \\
\hline \multicolumn{5}{|l|}{ Youths' life satisfaction } \\
\hline Youth-report & 34.53 & 6.95 & 34.20 & 6.54 \\
\hline Parent-report & 33.94 & 4.87 & - & - \\
\hline
\end{tabular}

(see Table 3), indicating total mean levels of negative self-schemas at Time 1 were not significantly different from total mean levels of negative self-schemas at Time 2 .

Stability of Positive Self-Schemas Overall, positive self-schemas at Time 1 were significantly and positively correlated with positive self-schemas at Time $2(r=.44$, $p<.001$, see Table 2). In light of the comparatively sparse literature on positive selfschemas generally, the stability of specific positive self-schema themes was examined. There were significant and positive correlations between each of the five positive selfschema subscales at Time 1 and their associated subscales at Time 2 with large effect sizes. The nature of these correlations was as follows: worthiness $(r=.52, p<.001)$; trust $(r=.50, p<.001)$; success $(r=.42, p<.001)$; self-efficacy $(r=.41, p<.001)$; and optimism $(r=.39, p<.001)$.

In addition, paired samples $t$-tests were conducted to examine mean differences between total positive self-schemas and specific positive self-schema themes (see Table 3). No statistically significant differences emerged with the exception of the positive self-schema theme of optimism, such that youth reported significantly higher levels of optimism at Time 2, albeit with a small effect size (Cohen's $d=.24$, see Table 1 and Table 3).

Relation of Self-Schemas to Youth Functioning Over Time Correlations were examined to assess the prospective association of self-schemas at Time 1 to youths' functioning at Time 2 (see Table 2). Negative self-schemas at Time 1 were significantly, positively related to YR-DS at Time $2(r=.47, p<.001)$ such that higher levels of negative selfschemas at Time 1 associated with higher levels of YR-DS at Time 2. In contrast, positive self-schemas at Time 1 were significantly, negatively related to YR-DS at Time $2(r=-.39, p<.001)$. Higher levels of positive self-schemas at Time 1 characterized 


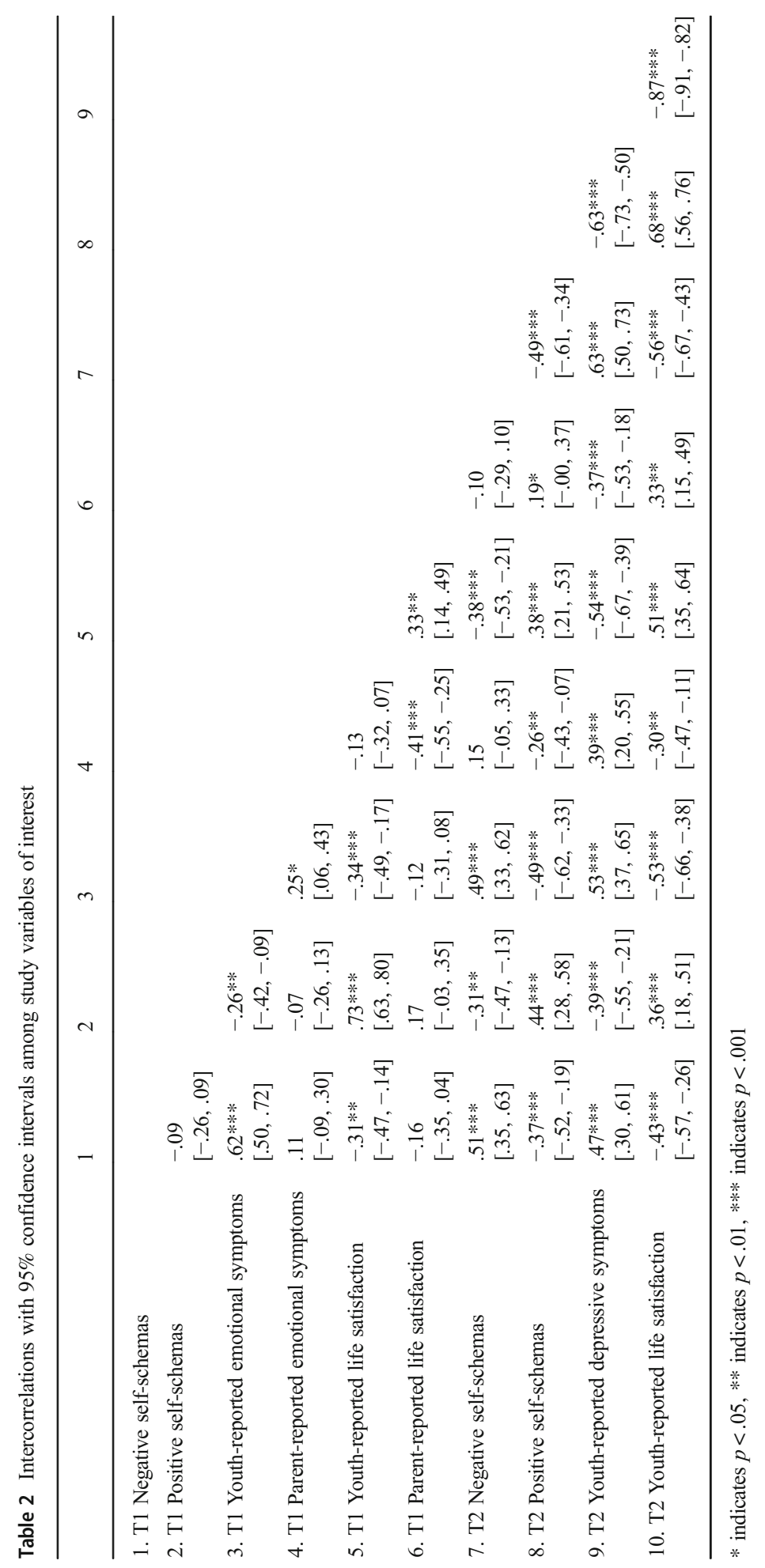


Table 3 Paired samples $t$-tests examining schema stability

\begin{tabular}{lc}
\hline & $t$ \\
\hline Negative self-schema total & 1.20 \\
Positive self-schema total & -1.96 \\
Worthiness & -1.18 \\
Trust & -1.30 \\
Success & -1.20 \\
Self-efficacy & -1.96 \\
Optimism & $-2.47^{*}$ \\
\hline
\end{tabular}

* indicates $p<.05$

lower levels of YR-DS at Time 2. Negative self-schemas at Time 1 were significantly, negatively related to YR-LS at Time $2(r=-.43, p<.001)$, suggesting higher levels of negative self-schemas at Time 1 were associated with lower levels of YR-LS at Time 2. Finally, positive self-schemas at Time 1 were significantly, positively related to YR-LS at Time $2(r=.36, p<.001)$, revealing higher levels of positive self-schemas at Time 1 were related to higher levels of YR-LS at Time 2.

\subsection{Multivariate Relations}

To further understand the prospective associations of self-schemas with youth functioning and whether positive self-schemas at Time 1 provide unique incremental information regarding youth functioning at Time 2 beyond negative self-schemas, a series of hierarchical multiple regressions were conducted. Data for all models adhered to statistical assumptions (e.g., no evidence of multicollinearity, evidence for additivity, acceptable Cook's distance, VIF and Tolerance values).

Self-Schemas as Predictors of Youths' Emotional Functioning The first model examined the longitudinal associations of self-schemas in the context of YR-DS while controlling for gender, YR-ES, and PR-ES at Time 1 (see Table 4). Gender, YR-ES, and PR-ES at Time 1 explained 35\% of the variance in YR-DS at Time 2. Negative self-schemas at Time 1 explained an additional $4 \%$ of the variance in YR-DS at Time 2. Consistent with hypotheses, positive self-schemas at Time 1 contributed an additional $8 \%$ variance to YR-DS at Time 2, beyond Time 1 negative self-schemas, Time 1 YRES and PR-ES, and gender.

Self-Schemas as Predictors of Youths' Life Satisfaction The second model assessed the role of self-schemas in prospectively predicting YR-LS while controlling for YR-LS and PR-LS at Time 1 (see Table 4). YR-LS and PR-LS at Time 1 explained 29\% of the variance in YR-LS at Time 2. Negative self-schemas at Time 1 explained an additional $8 \%$ of the variance in YR-LS at Time 2. Contrary to hypotheses, positive self-schemas at Time 1 did not contribute any additional variance to the prediction of YR-LS at Time 2 beyond Time 1 negative self-schemas, Time 1 YR-LS and PR-LS. 


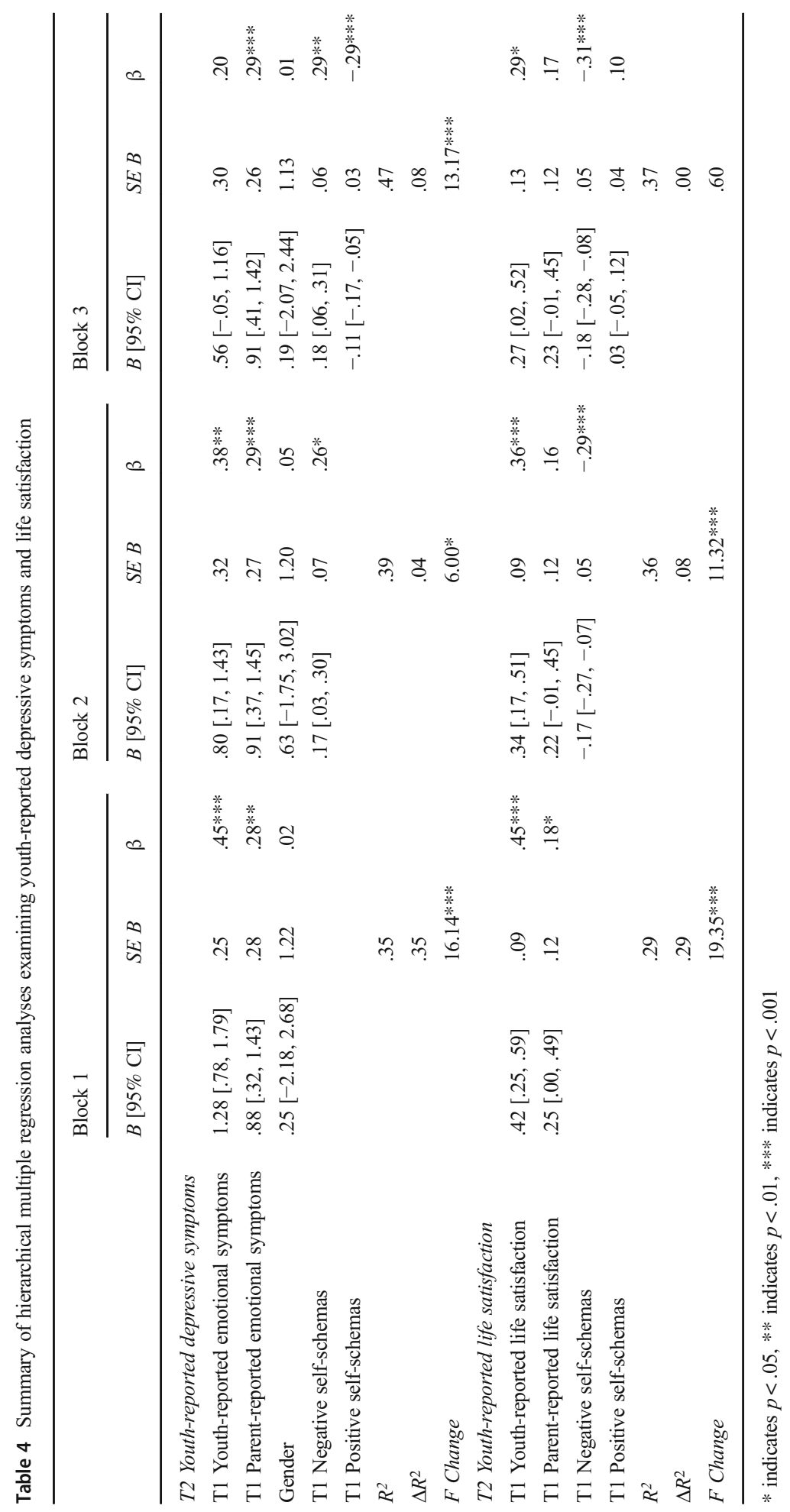




\section{Discussion}

The present study is the first to evaluate the longitudinal relations of positive and negative self-schemas in the context of youth- and parent-reports of children and adolescents' depressive symptoms and well-being. In this way, the study aligns with the theoretical frameworks of positive (clinical) psychology (Seligman and Csikszentmihalyi 2000; Wood and Tarrier 2010) and positive youth development (Larson 2000, 2006; Lerner et al. 2005). Together, these findings contribute novel information to extant understanding of children and adolescents' self-schemas and confer a more refined account of the presaging role of cognition for indicators of youths' psychopathology and well-being. Further, some of our findings replicate results from previous studies, contributing to the accumulation of knowledge regarding self-schemas and youths' functioning (Maxwell et al. 2015).

\subsection{Consistency of Self-Schemas during Childhood and Adolescence}

A primary goal of this study was to shed light on the general stability of self-schema content in youth. Results suggest children and adolescents' negative and positive selfschemas and specific positive self-schema themes exhibited stability over time, confirming hypotheses and previous research with adults (e.g., Dozois and Dobson 2001), adolescents (Hankin 2008) and children (Goldstein et al. 2015; Hayden et al. 2013) and lending validity to Friedmann et al.'s (2016) findings. Similar to Friedmann et al. (2016), total levels of negative and positive self-schemas and specific positive self-schema themes (with the exception of optimism) did not show significant differences over time, providing preliminary evidence for the consistency of most selfschema content by early adolescence.

Optimism is defined as one's belief that life outcomes will be favourable, or the ability to identify positive aspects of difficult or unfavourable situations (Keyfitz et al. 2013; Scheier and Carver 1985). The timing of data collection (fall and spring, respectively) may explain why youth reported comparatively higher self-beliefs of optimism later in the school year as early adjustment stressors may have eased. Over interpretation of this result is cautioned given the relatively small effect size and measurement at only two time points.

Despite the conceptualization of adolescence as a time of "storm and stress" during which youth are experimenting with identity formation (Brinthaupt and Lipka 2002; Meeus 2011; Swanson et al. 1998), the present study implies the makeup of child and adolescents' self-schemas are relatively consistent over time. Although higher levels of negative self-schemas are theorized to be amenable to modification, it is unclear whether comparatively lower levels of positive self-schemas are as responsive to modification. A future research goal will be to identify ideal timing for preventative cognitive self-schema restructuring, and accumulating knowledge about self-schema stability will be informative in this regard.

\subsection{Child and Adolescent Self-Schemas and Prospective Associations with Depressive Symptoms}

An additional objective of this study was to consider the potentially dissociable roles of positive and negative self-schemas in the context of children and adolescents' 
depressive symptoms over time. Consistent with hypotheses and previous research (Friedmann et al. 2016; Jaenicke et al. 1987; Keyfitz et al. 2013; Prieto et al. 1992; Shirk et al. 1998; Whitman and Leitenberg 1990), positive self-schemas at Time 1 were inversely related to children and adolescents' depressive symptoms at Time 2 . Relatedly, higher levels of negative self-schemas at Time 1 were associated with higher levels of children and adolescents' depressive symptoms at Time 2, a finding commensurate with a large body of literature supporting this association (Abela and Sullivan 2003; Carter and Garber 2011; Hankin et al. 2004; Lumley and Harkness 2007). Further, in a multivariate context, positive self-schemas at Time 1 explained an additional $8 \%$ unique variance in YR-DS at Time 2, even after controlling for Time 1 negative self-schemas, YR-ES, PR-ES, and gender. Negative self-schemas alone only accounted for $4 \%$ variance in youths' depressive symptomatology. These findings are in accordance with hypotheses and previous research emphasizing the utility of positive constructs in predicting children and adolescents' depressive symptoms (Bandura et al. 1999; Dunn et al. 2009; Gruber et al. 2017; Keyfitz et al. 2013; Muris 2002; Whitman and Leitenberg 1990). For children and adolescents, lower levels of positive selfschemas may be an equal if not stronger predictor of depressive symptomatology compared to higher levels of negative self-schemas.

Although models of cognitive vulnerability to depression have focused almost exclusively on negative self-schemas, the results of the present study suggest integrating positive self-schemas into developmental models of child and adolescent depression is necessary. In particular, these cognitive findings align with Clark and Watson's (1991) tripartite model of affect, whereby depression is defined primarily by low positive affect, whereas other emotional disorders such as anxiety share the presence of high negative affect. In this way, positive affect shows specificity in characterizing depressive symptomatology. This model has been supported in child and adolescent samples (Conway et al. 2017; Gencoz et al. 2001; Gruber et al. 2017). The present results suggest cognitive self-schemas may have a dissociable function similar to that of affect. This study thus dovetails well with the tripartite model and extends this perspective by considering cognitive and affective qualities of youths' depressive symptoms.

\subsection{Self-Schemas as Prospective Predictors of Child and Adolescent Life Satisfaction}

Current research has signaled self-schemas may also provide pertinent information about child and adolescent well-being (Caprara et al. 2006; Mak et al. 2011; Robinson and Kirkeby 2005; Tomlinson et al. 2016). In keeping with hypotheses, positive selfschemas at Time 1 were significantly and positively related to child and adolescent life satisfaction at Time 2. Conversely, negative self-schemas at Time 1 were significantly and negatively related to youths' life satisfaction at Time 2. However, negative selfschemas emerged as the only unique predictor of youths' ratings of life satisfaction in a multivariate analysis. This finding is particularly surprising given positive variables tend to predict positive outcomes (e.g., Fredrickson 2001) and Tomlinson et al.'s (2016) cross-sectional finding that positive self-schemas explained $38 \%$ of the variance in adolescents' life satisfaction beyond negative self-schemas, age, and gender. However, there are some potential explanations.

The utility of positive self-schemas in predicting positive outcomes may be tempered relative to negative self-schemas over time, and may have stronger associations 
with positive outcomes in cross-sectional models (Tomlinson et al. 2016). Indeed, Friedmann et al. (2016) found negative self-schemas to be more potent predictors of youths' resilience across time compared to positive self-schemas. Some researchers have argued negative cognitions may serve as robust determinants of well-being by allowing individuals to maintain a level of balance and pragmatism about life expectations (Carroll et al. 2006; Peterson 2000; Wong 2010). These findings underscore the potentially complex longitudinal relations among positive and negative self-schemas and life satisfaction, and support inclusion of ostensibly positive and negative variables within the same models to best understand well-being (Gruman et al. 2017).

\subsection{Limitations}

Despite several strengths of the current study (i.e., longitudinal, multi-informant) some limitations are notable. First, the sample size did not allow for the effect of participant gender on central study variables to be explored. Given females reported significantly higher levels of YR-ES at Time 1 and a robust literature signaling gender differences in depression emerge during adolescence (Hankin et al. 1998; Gomez-Baya et al. 2017), such analyses would have been advantageous. Similarly, the sample size was insufficient to explore the contributions of specific positive self-schema themes to aspects of youths' functioning. Previous research (Keyfitz et al. 2013; Tomlinson et al. 2016) has identified that particular positive self-schema themes may differentially predict youth functioning, and such dissociable effects could add to theoretical models such as the cognitive content-specificity theory (Beck et al. 1987).

Aspects of the current study's methodology may limit the interpretation of the results. First, the current longitudinal study included only two time points. It is recommended that future research use longitudinal designs with a minimum of three time points to provide a more fine-grained understanding of the stability of children and adolescents' cognitive content. An additional methodological limitation of this study was the inability to provide a direct measure of YR-DS at Time 1, instead employing the Emotional Symptoms subscale of the SDQ. This limitation is partially mitigated by multiple informants reporting on youths' emotional symptoms at Time 1 . Further, this subscale is reliably associated with validated measures of adolescent depression and predicts children and adolescents' depressive symptoms (Alpaslan et al. 2016; Essau et al. 2013; Goodman 2001; Goodman et al. 2003; Muris et al. 2003; Tsang et al. 2012). YR-ES and PR-ES at Time 1 were also strongly related to YR-DS at Time 2. Together, it can be reasonably concluded that YR-ES and PR-ES as measured by the SDQ Emotional Symptoms subscale at Time 1 adequately controlled for YR-DS at Time 1 to explore the longitudinal relations between self-schemas and YR-DS in a multivariate framework.

Finally, the majority of this community sample of child and adolescents exhibited sub-clinical levels of depressive symptoms and moderate to high levels of life satisfaction, limiting generalizability to clinical populations. However, subclinical depression is impairing in its own right and is a potent predictor of future symptomatology within the clinical range (Fergusson et al. 2005; Georgiades et al. 2006; Gotlib et al. 1995; Harrington et al. 1990). Thus, these findings provide important information about factors relevant to the early stages of child and adolescent depression and well-being. Related to issues of generalizability is the observed low response rate, which may suggest a self-selection bias and reduce the generalizability of the results. 


\subsection{Future Directions and Implications}

These findings support conceptualizing positive and negative self-schemas on related yet separate continua given self-schemas were distinguishably related to children and adolescents' functioning (MacLeod and Moore 2000). Future research should consider whether and how positive and negative self-schemas share similar mechanisms in conferring risk and vulnerability for depression and fomenting well-being over time. Future studies should also examine these variables across a longer period of time and include multiple time points during which self-schemas and functioning can be assessed. In this way, the methodological approach employed by Goldstein et al. (2015) and Hayden et al. (2013) may useful to examine self-schema stability in future research, whereby a specific cohort of youth is followed over a longer period of time. Although the present study focused on self-schema content, future studies should examine self-schema content and organization and employ indirect self-schema measures (e.g., psychological distance scaling task [PDST; Dozois and Dobson 2001; youth version Lumley et al. 2012], self-referent encoding task [SRET; Kuiper and Derry 1982]), and determine whether these facets of self-schemas similarly or differentially predict youths' functioning. Finally, future studies ought to consider gradations of selfschemas (i.e., moderate vs. extreme) given the presence of extreme positive cognitions may not necessarily incite adaptive outcomes (Gruman et al. 2017; Steffen et al. 2016; Vazquez 2017).

The current study provides an account of positive and negative self-schema content in the context of a more holistic model of child and adolescent mental health and wellbeing, adding to extant knowledge by offering evidence for the stability of child and adolescent self-schemas. Further, while a lack of positive self-schemas may be a more potent longitudinal predictor of adolescents' depressive symptoms - adding support and cognitive nuances to Clark and Watson's (1991) tripartite model - negative selfschemas may be more useful in projections of life satisfaction. These results highlight the value of undertaking balanced empirical research examining positivity and negativity within psychopathology and well-being, exemplify how positive and negative self-schemas offer incremental heuristic value about indices of youths' functioning. With replication, these findings may provide meaningful avenues for investigating the prophylactic role of self-schemas in psychopathology and identifying the most appropriate timing of interventions designed to harness self-schemas to bolster child and adolescent well-being.

Acknowledgements We are grateful to the Wellington Catholic District School Board for their support of our research and to the youth and parents who participated in this project. We are also grateful to all the members of the Resilient Youth Research Group for their research efforts towards the completion of this research project.

Funding This work was supported by the Ontario Mental Health Foundation New Investigator Fellowship [grant number 049438] (second author).

\section{Compliance with Ethical Standards}

Conflict of Interest The authors declare that they have no conflict of interest. 
Ethical Approval All procedures performed in studies involving human participants were in accordance with the ethical standards of the institutional and/or national research committee and with the 1964 Helsinki declaration and its later amendments or comparable ethical standards.

\section{References}

Abela, J. R. Z., \& Hankin, B. L. (2008). Handbook of depression in children and adolescents. New York: Guilford Press.

Abela, J. R. Z., \& Sullivan, C. (2003). A test of Beck's cognitive diathesis-stress theory of depression in early adolescents. Journal of Early Adolescence, 23(4), 384 404. https://doi.org/10.1177/0272431603258345.

Alpaslan, A. H., Kocak, U., \& Avci, K. (2016). Gender-related factors for depressive symptoms in Turkish adolescents. Journal of Child and Adolescent Psychiatric Nursing, 29(1), 23-29. https://doi.org/10.1111 /jcap. 12131.

Bandura, A., Pastorelli, C., Barbaranelli, C., \& Caprara, G. V. (1999). Self-efficacy pathways to childhood depression. Personality Process and Individual Differences, 76(2), 258-269.

Beck, A. T. (1967). Depression. New York: Harper and Row.

Beck, A. T. (1987). Cognitive models of depression. Journal of Cognitive Psychotherapy, 1(1), 5-37.

Beck, A. T., Brown, G., Steer, R. A., Eidelson, J. I., \& Riskind, J. H. (1987). Differentiating anxiety from depression: A test of the cognitive content-specificity hypothesis. Journal of Abnormal Psychology, 96(3), $179-183$.

Brinthaupt, T. M., \& Lipka, R. P. (2002). Understanding early adolescent self and identity: An introduction. In R. P. Lipka \& T. M. Brinthaupt (Eds.), Understanding early adolescent self and identity: Applications and interventions (pp. 1-21). Albany: State University of New York Press.

Calvete, E., Orue, I., \& González-Diez, Z. (2012). An examination of the structure and stability of early maladaptive schemas by means of the young Schema Questionnaire-3. European Journal of Psychological Assessment, 29(4), 283-290. https://doi.org/10.1027/1015-5759/a000158.

Calvete, E., Orue, I., \& Hankin, B. L. (2015). A longitudinal test of the vulnerability-stress model with early maladaptive schemas for depressive and social anxiety symptoms in adolescents. Journal of Psychopathology and Behavioral Assessment, 37(1), 85-99. https://doi.org/10.1007/s10862-014-9438-x.

Caprara, G. V., Steca, P., Gerbino, M., Paciello, M., \& Vecchio, G. M. (2006). Looking for adolescents' wellbeing: Self-efficacy beliefs as determinants of positive thinking and happiness. Epidemiologia $e$ Psichiatra Sociale, 15(1), 30-43. https://doi.org/10.1017/S1121189X00002013.

Carroll, P., Sweeny, K., \& Shepperd, J. A. (2006). Forsaking optimism. Review of General Psychology, 10(1), 56-73. https://doi.org/10.1037/1089-2680.10.1.56.

Carter, J. S., \& Garber, J. (2011). Predictors of the first onset of a major depressive episode and changes in depressive symptoms across adolescence: Stress and negative cognition. Journal of Abnormal Psychology, 120(4), 779-796. https://doi.org/10.1037/a0025441.

Clark, L. A., \& Watson, D. (1991). Tripartite model of anxiety and depression: Psychometric evidence and taxonomic implications. Journal of Abnormal Psychology, 100(3), 316-336.

Conway, C. C., Zinbarg, R. E., Mineka, R. E. Z., \& Craske, M. G. (2017). Core dimensions of anxiety and depression change independently during adolescence. Journal of Abnormal Psychology, 126(2), 160-172. https://doi.org/10.1037/abn0000222.

Diener, E. S. (2000). Subjective well-being: The science of happiness and a proposal for a national index. American Psychologist, 55(1), 34-43. https://doi.org/10.1037//0003-066X.55.1.3.

Dozois, D. J. A., \& Beck, A. T. (2008). Cognitive schemas, beliefs and assumptions. In K. S. Dobson \& D. J. A. Dozois (Eds.), Risk factors in depression (pp. 121-143). San Diego: Elsevier Academic Press.

Dozois, D. J. A., \& Dobson, K. S. (2001). A longitudinal investigation of information processing and cognitive organization in clinical depression: Stability of schematic interconnectedness. Journal of Consulting and Clinical Psychology, 69(6), 914-925.

Dulman, M., \& Ong, A. (2006). Editorial: New methodological directions for the study of adolescent competence and adaptation. Journal of Adolescence, 29(6), 851-856. https://doi.org/10.1016/j. adolescence.2006.09.006.

Dunn, B. D., Stefanovitch, I., Buchan, K., Lawrence, A. D., \& Dalgleish, T. (2009). A reduction in positive self-judgement bias is uniquely related to anhedonic symptoms of depression. Behaviour Research and Therapy, 47(5), 374-381. 
Essau, C. A., Olaya, B., Pasha, G., Gilvarry, C., \& Bray, D. (2013). Depressive symptoms among children and adolescents in Iran: A confirmatory factor analytic study of the Centre for Epidemiological Studies Depression Scale for children. Child Psychiatry and Human Development, 44(1), 123-136. https://doi. org/10.1007/s10578-012-0314-1.

Fergusson, D. M., Horwood, L. J., Riddler, E. M., \& Beautrais, A. L. (2005). Subthreshold depression in adolescence and mental health outcomes in adulthood. Archives of General Psychiatry, 62(1), 66-72. https://doi.org/10.1001/archpsyc.62.1.66.

Fredrickson, B. L. (2001). The role of positive emotions in positive psychology: The broaden-and-build theory of positive emotions. American Psychologist, 56(3), 218-226. https://doi.org/10.1037/0003-066 X.56.3.218.

Friedmann, J. S., Lumley, M. N., \& Lerman, B. (2016). Cognitive schemas as longitudinal predictors of selfreported adolescent depressive symptoms and resilience. Cognitive Behaviour Therapy, 45(1), 32-48. https://doi.org/10.1080/16506073.2015.1100212.

Garber, J., Weiss, B., \& Shanley, N. (1993). Cognitions, depressive symptoms, and development in adolescents. Journal of Abnormal Psychology, 102(1), 47-57.

Gencoz, T., Voelz, Z. R., Gencoz, F., Pettit, J. W., \& Joiner, T. E. (2001). Specificity of information processing styles to depressive symptoms in youth psychiatric inpatients. Journal of Abnormal Child Psychology, 29(3), 255-262. https://doi.org/10.1023/A:1010385832566.

Georgiades, K., Lewinsohn, P. M., Monroe, S. M., \& Seeley, J. R. (2006). Major depressive disorder in adolescence: The role of subthreshold symptoms. Journal of the American Academy of Child and Adolescent Psychiatry, 45(8), 936-944. https://doi.org/10.1097/01.chi.0000223313.25536.47.

Goldstein, B. L., Hayden, E. P., \& Klein, D. N. (2015). Stability of self-reference encoding task performance and associations with change in depressive symptoms from early to middle childhood. Cognition and Emotion, 29(8), 1445-1455. https://doi.org/10.1080/02699931.2014.990358.

Gomez-Baya, D., Mendoza, R., Paino, S., \& Gillham, J. E. (2017). A two-year longitudinal study of gender differences in responses to positive affect and depressive symptoms during middle adolescence. Journal of Adolescence, 56, 11-23. https://doi.org/10.1016/j.adolescence.2017.01.005.

Goodman, R. (1997). The strengths and difficulties questionnaire: A research note. Journal of Child Psychology and Psychiatry, 38(5), 581-586.

Goodman, R. (2001). Psychometric properties of the strengths and difficulties questionnaire. Journal of the American Academy of Child and Adolescent Psychiatry, 40(11), 1137-1345. https://doi.org/10.1097 /00004583-200111000-00015.

Goodman, R., Ford, T., Simmons, H., Gatward, R., \& Meltz, H. (2003). Using the strengths and difficulties questionnaire (SDQ) to screen for child psychiatric disorders in a community sample. International Review of Psychiatry, 15(1-2), 162-172.

Gotlib, I. H., Lewinsohn, P. M., \& Seeley, J. R. (1995). Symptoms versus a diagnosis of depression: Differences in psychosocial functioning. Journal of Consulting and Clinical Psychology, 63(1), 90-100.

Gruber, J., Meter, A. V., Gilbert, K. E., Youngstrom, E. A., Youngstrom, J. K., Feeny, N. C., \& Findling, R. L. (2017). Positive emotion specificity and mood symptoms in an adolescent outpatient sample. Cognitive Therapy and Research, 41(3), 393-405. https://doi.org/10.1007/s10608-016-9796-7.

Gruman, J. A., Lumley, M. N., \& Gonzales-Morales, G. (2017). Incorporating balance: Challenges and opportunities for positive psychology. Canadian Psychology. https://doi.org/10.1037/cap0000109.

Hammen, C., \& Zupan, B. A. (1984). Self-schemas, depression, and the processing of personal information in children. Journal of Experimental Child Psychology, 37(3), 598-608.

Hankin, B. L. (2008). Stability of cognitive vulnerabilities to depression. A short-term prospective multiwave study. Journal of Abnormal Psychology, 117, 324-333. https://doi.org/10.1037/0021-843X.117.2.324.

Hankin, B. L., Abramson, L. Y., Moffit, T. E., Silva, P. A., McGee, R., \& Angell, K. E. (1998). Development of depression from preadolescence to young adulthood: Emerging gender differences in a 10-year longitudinal study. Journal of Abnormal Psychology, 107(1), 128-140.

Hankin, B. L., Abramson, L. Y., Miller, N., \& Haeffel, G. J. (2004). Cognitive vulnerability-stress theories of depression: Examining affective specificity in the prediction of depression versus anxiety in three prospective studies. Cognitive Therapy and Research, 28(3), 309-345. https://doi.org/10.1023 /B:COTR.0000031805.60529.0d.

Harrington, R. C., Fudge, H., Rutter, M., Pickles, A., \& Hill, J. (1990). Adult outcome of childhood and adolescent depression: I. psychiatric status. Archives of General Psychiatry, 47(5), 465-473.

Hayden, E. R., Olino, T. M., Mackrell, S. V. M., Jordan, P. L., Desjardins, J., \& Katsiroumbas, P. (2013). Cognitive vulnerability to depression during middle childhood: Stability and associations with maternal affective styles and parental depression. Personality and Individual Differences, 55(8), 892-897. https://doi.org/10.1016/j.paid.2013.07.016. 
Huebner, E. S., Valois, R. F., Suldo, S. M., Smith, L. C., McKnight, C. G., Seligson, J. L., \& Zullig, K. J. (2004). Perceived quality of life: A neglected component of adolescent health assessment and intervention. Journal of Adolescent Health, 34(4), 270-278. https://doi.org/10.1016/j.jadohealth.2003.07.007.

Jaenicke, C., Hammen, C., Zupan, B., Hiroto, D., Gordon, D., Adrian, C., \& Burge, D. (1987). Cognitive vulnerability in children at risk for depression. Journal of Abnormal Child Psychology, 15(4), 559-575.

Johnson, J., \& Wood, A. M. (2017). Integrating positive and clinical psychology: Viewing human functioning as continua from positive to negative can benefit clinical assessment, interventions and understandings of resilience. Cognitive Therapy and Research, 41(3), 335-349. https://doi.org/10.1007/s10608-015-9728-y.

Kercher, A. J., Rapee, R. M., \& Schniering, C. A. (2009). Neuroticism, life events and negative thoughts in the development of depression in adolescent girls. Journal of Abnormal Child Psychology, 37(7), 903-915. https://doi.org/10.1007/s10802-009-9325-1.

Kessler, R. C., Avenevoli, S., \& Merikangas, K. R. (2001). Mood disorders in children and adolescents: An epidemiologic perspective. Biological Psychiatry, 49(12), 1002-1014. https://oi.org/10.1016/S00063223(01)01129-5.

Keyes, C. L. M. (2002). The mental health continuum: From languishing to flourishing in life. Journal of Health and Social Behavior, 43(2), 207-222.

Keyes, C. L. M. (2006). Mental health in adolescence: Is America's youth flourishing? American Journal of Orthopsychiatry, 76(3), 395-402. https://doi.org/10.1037/0002-9432.76.3.395.

Keyes, C. L. M. (2007). Promoting and protecting mental health as flourishing: A complementary strategy for improving national mental health. American Psychologist, 62(2), 95-108. https://doi.org/10.1037/0003066X.62.2.95.

Keyfitz, L., Lumley, M. N., Hennig, K. H., \& Dozois, D. J. A. (2013). The role of positive schemas in child psychopathology and resilience. Cognitive Therapy and Research, 37(1), 97-108. https://doi.org/10.1007 /s10608-012-9455-6.

Kovacs, M. (1981). Rating scales to assess depression in school-aged children. Acta Paedopsychiatry, 46(56), 305-315.

Kuiper, N. A., \& Derry, P. A. (1982). Depressed and nondepressed content self-reference in mild depressives. Journal of Personality, 50(1), 67-80.

Larson, R. W. (2000). Toward a psychology of positive youth development. American Psychologist, 55(1), 170-183. https://doi.org/10.1037//0003-066X,55.1.170.

Larson, R. W. (2006). Positive youth development, willful adolescents, and mentoring. Journal of Community Psychology, 34(6), 677-689. https://doi.org/10.1002/jcop.20123.

Lerner, R. M., Lerner, J. V., Almerigi, J. B., Theokas, C., Phelps, E., Gestsdottir, S., et al. (2005). Positive youth development, participation in community youth development programs, and community contributions of fifth-grade adolescents: Findings from the first wave of the 4-H study of positive youth development. Journal of Early Adolescence, 25, 17-71. https://doi.org/10.1177/0272431604272461.

Lewinsohn, P. M., Joiner, T. E., \& Rohde, P. (2001). Evaluation of cognitive diathesis-stress models in predicting major depressive disorder in adolescents. Journal of Abnormal Psychology, 110(2), 203-213. https://doi.org/10.1037//0021-843X.110.2.203.

Lumley, M. N., \& Harkness, K. L. (2007). Specificity in the relations among childhood adversity, early maladaptive schemas, and symptom profiles in adolescent depression. Cognitive Therapy and Research, 31(5), 639-657. https://doi.org/10.1007/s10608-006-9100-3.

Lumley, M. N., Dozois, D. J. A., Hennig, K. H., \& Marsh, A. (2012). Cognitive organization, perceptions of parenting and depression symptoms in early adolescence. Cognitive Therapy and Research, 36(4), 300310. https://doi.org/10.1007/s10608-011-9365-z.

MacLeod, A. K., \& Moore, R. (2000). Positive thinking revisited: Positive cognitions, well-being and mental health. Clinical Psychology and Psychotherapy, 7(1), 1-10. https://doi.org/10.1002/(SICI)1099-0879 (200002)7:1<1::AID-CPP228>3.0.CO;2-S.

Mak, W. W. S., Ng, I. S. W., \& Wong, C. C. Y. (2011). Resilience: Enhancing well-being through the positive cognitive triad. Journal of Counseling Psychology, 58(4), 610-617. https://doi.org/10.1037/a0025195.

Maxwell, S. E., Lau, M. Y., \& Howard, G. S. (2015). Is psychology suffering from a replication crisis? What does "failure to replicate" really mean? American Psychologist, 70(6), 487-498. https://doi.org/10.1037 /a0039400.

McClain, L., \& Abramson, L. Y. (1995). Self-schemas, stress, and depressed mood in college students. Cognitive Therapy and Research, 19(4), 419-432. https://doi.org/10.1007/BF02230409.

McKnight, C. G., Huebner, E. S., \& Suldo, S. (2002). Relationships among stressful life events, temperament, problem behavior, and global life satisfaction in adolescents. Psychology in the Schools, 39(6), 677-687. https://doi.org/10.1002/pits.10062. 
Meeus, W. (2011). The study of adolescent identity formation 2000-2010: A review of longitudinal research. Journal of Research on Adolescence, 21(1), 75-94.

Muris, P. (2002). Relationships between self-efficacy and symptoms of anxiety disorders and depression in a normal adolescent sample. Personality and Individual Differences, 32, 337-348. https://doi.org/10.1016 /S0191-8869(01)00027-7.

Muris, P., Meesters, C., \& van den Berg, F. (2003). The strengths and difficulties questionnaire (SDQ): Further evidence for its reliability and validity in a community sample of Dutch children and adolescents. European Child \& Adolescent Psychiatry, 12(1), 1-8. https://doi.org/10.1007/s00787-003-0298-2.

O’Connor, M., Sanson, A., Hawkins, M. T., Toumbourou, J. W., Letcher, P., \& Frydenberg, E. (2011). Differentiating three conceptualisations of the relationship between positive development and psychopathology during the transition to adulthood. Journal of Adolescence, 34(3), 475-484. https://doi. org/10.1016/j.adolescence.2010.06.005.

Park, N. (2004). The role of subjective well-being in positive youth development. The ANNALS of the American Academy of Political and Social Science, 591(1), 25-39. https://doi.org/10.1177 /0002716203260078.

Pawelski, J. O. (2016). Defining the 'positive' in positive psychology: Part II. A normative analysis. The Journal of Positive Psychology, 11(4), 357-365. https://doi.org/10.1080/17439760.2015.1137628.

Petersen, I. T., Lindhiem, O., LeBeau, B., Bates, J. E., Pettit, G. S., Lansford, J. E., \& Dodge, K. A. (2018). Development of internalizing problems from adolescence to emerging adulthood: Accounting for heterotypic continuity with vertical scaling. Developmental Psychology, 54(3), 586-599. https://doi.org/10.1037 /dev0000449.

Peterson, C. (2000). The future of optimism. American Psychologist, 55(1), 44-55.

Prieto, S. L., Cole, D. A., \& Tageson, C. W. (1992). Depressive self-schemas in clinic and nonclinic children. Cognitive Therapy and Research, 16(5), 521-534. https://doi.org/10.1007/BF01175139.

Proctor, C. L., Linley, P. A., \& Maltby, J. (2009). Youth life satisfaction: A review of the literature. Journal of Happiness Studies, 10(5), 583-630. https://doi.org/10.1007/s10902-008-9110-9.

Renshaw, T. L., Furlong, M. J., Dowdy, E., Rebelez, J., Smith, D. C., O’Malley, M., et al. (2014). Covitality: A synergistic conception of adolescents' mental health. In M. J. Furlong, R. Gilman, \& E. S. Huebner (Eds.), Handbook of positive psychology in schools (2nd ed., pp. 12-32). New York: Routledge.

Rijkeboer, M. M., \& de Boo, G. M. (2010). Early maladaptive schemas in children: Development and validation of the schema inventory for children. Journal of Behavior Therapy and Experimental Psychiatry, 41(2), 102-109. https://doi.org/10.1016/j.jbtep.2009.11.001.

Robinson, M. D., \& Kirkeby, B. S. (2005). Happiness as a belief system: Individual differences and priming in emotional judgments. Personality and Social Psychology Bulletin, 31(8), 1134-1144. https://doi. org/10.1177/0146167204274081.

Scheier, M. F., \& Carver, C. S. (1985). Optimism, coping, and health: Assessment and implications of generalized outcome expectancies. Health Psychology, 4(3), 219-427.

Seligman, M. E. P., \& Csikszentmihalyi, M. (2000). Positive psychology: An introduction. Am Psychol, 55(1), 5-14. https://doi.org/10.1037//0003-066X.55.1.5.

Seligson, J. L., Huebner, E. S., \& Valois, R. F. (2003). Preliminary validation of the brief multidimensional students' life satisfaction scale (BMSLSS). Social Indicators Research, 61(2), 121-145. https://doi. org/10.1023/A:1021326822957.

Shirk, S. R., Boergers, J., Eason, A., \& Van Horn, M. (1998). Dysphoric interpersonal schemata and preadolescents' sensitization to negative events. Journal of Clinical Child Psychology, 27(1), 54-68. https://doi.org/10.1207/s15374424jccp2701_7.

Stallard, P. (2007). Early maladaptive schemas in children: Stability and differences between a community and a clinic referred sample. Clinical Psychology and Psychotherapy, 14(1), 10-18. https://doi.org/10.1016/j. jbtep.2009.11.001.

Stallard, P., \& Rayner, H. (2005). The development and preliminary evaluation of a schema questionnaire for children (SQC). Behavioural and Cognitive Psychotherapy, 33(2), 217-224. https://doi.org/10.1017 /S1352465804001912.

Steffen, P. R., Elliot, C. H., Lassen, M. K., Olsen, J., \& Smith, L. (2016). Expanding schema conceptualisation and assessment: Towards a richer understanding of adaptive and maladaptive functioning. Australian Journal of Psychology. https://doi.org/10.1111/ajpy.12141.

Swanson, D. P., Spencer, M. B., \& Petersen, A. (1998). Identity formation in adolescence. In K. Borman \& B. Schneider (Eds.), The adolescent years: Social influences and educational challenges (pp. 18-41). Chicago: University of Chicago Press. 
Timbremont, B., \& Braet, C. (2006). Brief report: A longitudinal investigation of the relation between a negative cognitive triad and depressive symptoms in youth. Journal of Adolescence, 29(3), 453-458. https://doi.org/10.1016/j.adolescence.2005.08.005.

Tomlinson, R. M., Keyfitz, L., Rawana, J. S., \& Lumley, M. N. (2016). Unique contributions of positive schemas for understanding child and adolescent life satisfaction and happiness. Journal of Happiness Studies. https://doi.org/10.1007/s10902-016-9776-3.

Tsang, K. L. V., Wong, P. Y. H., \& Lo, S. K. (2012). Assessing psychosocial well-being of adolescents: A systematic review of measuring instruments. Child: Care, Health, and Development, 38(5), 629-646. https://doi.org/10.1111/j.1365-2214.2011.01355.x.

Valois, R. F., Zullig, K. J., Huebner, E. S., \& Drane, J. W. (2001). Relationship between life satisfaction and violent behaviors among adolescents. American Journal of Health Behavior, 25(4), 353-366.

Vazquez, C. (2017). What does positivity add to psychopathology? An introduction to the special issue on 'positive emotions and cognitions in clinical psychology'. Cognitive Therapy and Research, 41(3), 325334. https://doi.org/10.1007/s10608-017-9847-8.

Whitman, P. B., \& Leitenberg, H. (1990). Negatively biased recall in children with self-reported symptoms of depression. Journal of Abnormal Child Psychology, 18(1), 15-27. https://doi.org/10.1007/BF00919453.

Wong, S. S. (2010). States of mind in psychopathology and psychological well-being. Journal of Psychopathology and Behavioural Assessment, 32(2), 178-184. https://doi.org/10.1007/s10862-0099148-y.

Wood, A. M., \& Tarrier, N. (2010). Positive clinical psychology: A new vision and strategy for integrated research and practice. Clinical Psychology Review, 30(7), 819-829. https://doi.org/10.1016/j. cpr.2010.06.003.

Zullig, K. J., Valois, R. F., Huebner, E. S., Oeltmann, J. E., \& Drane, J. W. (2001). Relationship between perceived life satisfaction and adolescents' substance abuse. Journal of Adolescent Health, 29(4), 279288. https://doi.org/10.1016/S1054-139X(01)00269-5.

Publisher's Note Springer Nature remains neutral with regard to jurisdictional claims in published maps and institutional affiliations. 